\title{
Primum cognitum, primum volitum, primum electum (I)
}

\author{
Primum Cognitum, Primum Volitum, Primum Electum (I)
}

Tomás Melendo Granados

Catedrático de Filosofía (Metafísica)

Universidad de Málaga

tmelendo@uma.es

Resumen

El carácter finito de las facultades humanas hace que, para ejercer rectamente sus funciones, necesiten el refuerzo de determinados hábitos. El artículo estudia con cierto detalle los hábitos primarios y fundamentales del entendimiento (primum cognitum) y de la voluntad (primum volitum y primum electum).

Palabras clave: hábito, entendimiento, voluntad, conocimiento, amor

Abstract

The limited character of human faculties makes it necessary for its operations to be reinforced by certain habits. The paper studies in detail the primary and fundamental habits of the intellect (primum cognitum) and of the will (primum volitum and primum electum.)

Keywords: habit, intellect, will, knowledge, love 
Justo porque la mejor metafísica surge de la reflexión sobre lo cotidiano, y a lo cotidiano retorna, en el desarrollo de este artículo deseo partir de una situación existencial nada extraordinaria - la boda entre dos personas- y de la interpretación antropológico-jurídica que comúnmente se le atribuye.

Según numerosos canonistas, el núcleo de la alianza matrimonial lo compondría la transformación de los novios en cónyuges o esposos; o, desde una perspectiva complementaria y más pertinente para los fines que me propongo, su efecto principal sería la conversión del amor de los contrayentes, esencialmente no-debido hasta el momento de la boda, en un amor ahora ya sí-obligado, al que los nuevos cónyuges se comprometen de por vida, mediante el acto de libre entrega de toda su persona sexuada y en cuanto sexuada: persona masculina y persona femenina.

Como explica Viladrich,

Ese acto de la voluntad - por lo mismo nuevo, original e irrepetible- no es tanto uno más de los actos pasados o futuros de quererse, cuanto de querer quererse. Es un compromiso de amor que convierte en comprometido al amor. Los amantes son los que se quieren, los esposos los que, además, se comprometen a quererse. ${ }^{1}$

A lo que añade:

Amarse hasta el extremo de "deberse" amor, es la máxima expresión del amor posible en la pareja humana. Por eso, comprometer el amor a título de deuda es, además de su inédito y máximo acto de amor, la expresión fundacional del matrimonio. ${ }^{2}$

\section{1. ¿Qué significa casarse?: perspectiva antropológico-metafísica}

\subsection{Lo importante es el amor}

Siendo verdad lo que acabo de resumir, no lo es menos algo que con frecuencia ni tan siquiera se nombra, pero que constituye el cimiento y la condición de posibilidad de lo que habitualmente tiende a subrayarse. A saber y en un primer acercamiento: que el sí verbal y existencial de los recién estrenados cónyuges no solo hace surgir la obligación gozosa de amarse mientras vivan, sino que, simultáneamente y con cierta prioridad de naturaleza, torna posible esa entrega incondicionada y fecunda.

Visto desde el extremo opuesto: los excesivos fracasos conyugales que se suceden en la actualidad, y, sobre todo, la mucha mayor frecuencia con que rompen los lazos quienes se han unido en convivencia cuasi matrimonial pero sin casarse, llevan a ad-

\footnotetext{
${ }^{1}$ VILAdrich, Pedro Juan: El pacto conyugal. Madrid: Rialp, 1990, p. 25.

${ }^{2} I b$., p. 34.
} 
vertir nítidamente que la pretensión de obligarse a amar para siempre a otra persona con total independencia de las circunstancias por las que una y otra atraviesen, si no fuera acompañada de un robustecimiento de la recíproca capacidad de amar, resultaría, en el fondo, una sublime ingenuidad, una niñada, casi una demencia.

El sentir colectivo lo intuye vagamente, aunque desorientado por la contracultura imperante. Por eso, desde hace ya bastantes años, se viene poniendo en duda en qué contribuye el acto de casarse al éxito de la futura vida en común; lo que equivale a decir, casi siempre, que la boda no aporta nada a esa convivencia y que más vale, por tanto, limitarse a convivir maritalmente mientras las circunstancias lo aconsejen o permitan.

Como se sabe, este modo de encarar la cuestión encuentra claros fundamentos en la filosofía antimetafísica ${ }^{3}$ de los últimos siglos y en la ordenación jurídica a la que dio origen; $y$ ha provocado en la cultura actual un proceso de trivialización, que lleva a no considerar ni especulativa ni vitalmente el alcance y las consecuencias de mayor relieve de esta y muchas otras de las decisiones más fundamentales para la propia existencia. ${ }^{4}$

Respecto al asunto que nos ocupa, las cuestiones que se plantean son relativamente variadas y reciben distintos matices. Pero, en fin de cuentas, pueden resolverse en la afirmación, sostenida con más o menos aplomo y agresividad, de que, en lo que atañe al matrimonio, lo único que importa es el amor.

A esta tesis respondería en dos momentos.

a) El primero, admitiendo sin reservas que, en efecto, en la vida conyugal lo radicalmente importante es el amor... como también lo es en cualquier otro contexto personal y humano.

b) Pero añadiría de inmediato lo que considero la clave de todo el asunto: que, para poder amar como lo requiere el matrimonio, resulta imprescindible capacitarse; y que semejante habilitación comienza necesaria e ineludiblemente justo con el acto de

\footnotetext{
${ }^{3}$ El adjetivo "antimetafísica" quiere indicar que ese tipo de filosofía, al no considerar las modificaciones reales que generan en cada sujeto sus propias acciones - entre las que ocupa un lugar de relieve la alianza conyugal-, tornan cualquier compromiso meramente formal o vacío e irrelevante: el derecho se ve privado de su imprescindible apoyatura ontológica.

${ }^{4}$ Tal vez la manifestación más clara de esa banalización es la que acaba por reducir el acto de casarse - con toda la carga antropológica, ética y ontológica que lleva consigo: en fin de cuentas, una intensificación de la energía del propio acto de ser y de la correlativa capacidad de amar- a una mera cuestión de burocracia: el simple "pasar por el cura o el funcionario de turno", como suele tristemente expresarse.
} 
entrega mutua e incondicionada en el que, desde la perspectiva antropológico-ontológica en que pretendo situarme, consiste la boda. ${ }^{5}$

\subsection{Hacerse capaces de amar}

Un paso más. Si no yerro, en el ámbito predicamental, el acto de libre donación total y recíproca en que consiste la boda genera un hábito o virtud inicial, fuente a su vez de nuevas virtudes, y al que se encuentra aparejada una inédita relación mutua con alcance también jurídico; 6 por otra parte o casi en identidad, semejante hábito transforma a los novios, convirtiéndolos en esposos, $\mathrm{y}$, como consecuencia, vigoriza y robustece la voluntad, de modo que ya empieza a ser posible:

a) Quererse con un amor verdaderamente conyugal: fiel, de por vida y hondamente fecundo.

b) Y, como parte de esa misma capacitación, hacer del propio cuerpo vehículo y resello de la entrega de la persona toda, y convertir la unión corporal íntima en el acto más específico (no necesariamente el mayor) del amor entre los cónyuges.

Con otras palabras: tal como lo concibo, al convertirlos en esposos, el acto recíproco de libertad en que consiste la boda no solo instauraría entre los novios la libre e imperecedera obligación de amarse, que ya es mucho, sino que en cierto modo antes, según un orden de naturaleza, los tornaría capaces de asumir ese deber y darle cumplimiento a lo largo de los años.

Según acabo de sugerir, el primer enfoque es el habitual entre los mejores representantes del derecho canónico contemporáneo. Por el contrario, advertir que semejante obligarse resultaría ineficaz sin la habilitación previa que origina el mismo acto de recíproca donación-aceptación, y determinar la naturaleza ontológica de esa capacitación, es la novedad que acabo de esbozar y pretendo hacer explícita en las páginas que siguen. ${ }^{7}$

\footnotetext{
${ }^{5}$ Entiendo ésta, por tanto, como origen, fundamento o causa eficiente del matrimonio, al que a su vez consideraré - de acuerdo con el uso más común en castellano- como aquel estado en que se hallan los esposos una vez casados.

${ }^{6}$ Como apunté en una nota previa y ahora de nuevo sólo menciono, todo lo que sucede en los dominios predicamentales se sustenta, en el caso que nos ocupa, en una intensificación del acto personal de ser de ambos cónyuges.

${ }^{7}$ Cabe ilustrar ese deber-capacitación mediante un ejemplo correcto, aunque bastante temerario: el del mandamiento máximo y máximamente nuevo que Jesucristo impuso a sus discípulos en la Última Cena.

No es difícil advertir que semejante pretensión sería una auténtica chifladura si el Señor, en el momento de establecer el precepto, no incrementara de manera casi infinita la capacidad de amar del cristiano... o previera los medios para fortificarla y hacerla crecer y madurar. ¿Cómo, si no, pedir a unos simples hombres que quieran a los demás como el mismísimo Dios los ama: «Como Yo os he amado»?
} 


\subsection{Obligados "porque" capacitados}

Lo intentaré en dos fases:

a) Antes que nada, relacionando semejante habilitación con el primum cognitum de los clásicos, que a menudo denomino habitus entitatis, y cuya función es facultar de manera próxima e inmediata al ser humano para percibir la realidad no en función de sus propias apetencias, necesidades, aspiraciones, caprichos o coyunturas particulares, sino tal como efectivamente esa realidad es: como ente, por emplear un término técnico clásico y ya consagrado.

b) Después, esclareciendo el porqué de semejante comparación, así como sus límites. Comencemos por el primer punto.

\section{Inteligencia, voluntad... y sus hábitos respectivos}

\subsection{Paralelismo asimétrico}

Tal vez uno de los errores más frecuentes a la hora de intentar comprender la voluntad y cuanto con ella se relaciona sea el de instaurar un paralelismo con el entendimiento, que resulta demasiado estricto y, por lo mismo, forzado. ${ }^{8}$

En mi opinión, dos son las causas principales de este equívoco.

a) Por un lado, el hecho de que el entendimiento haya sido mucho más estudiado que la voluntad, entre otros motivos, porque resulta más fácil de analizar que ella. No en vano el acto reflejo de la inteligencia - ya sea consectario o estrictamente formal y provocado $-{ }^{9}$ es el de conocer el propio conocimiento. Mientras que el retorno

Pues algo análogo -no idéntico, ni mucho menos, porque toda analogía acentúa más la diferencia que la semejanza- sucede en la boda, también la que se lleva a cabo en el ámbito natural, que es a la que principalmente me estoy refiriendo. En el mismo instante en que pronuncian el sí, y por manifestarlo de manera libre y voluntaria, los recién estrenados cónyuges no solo se obligan, sino que sobre todo se tornan mutuamente capaces de (comenzar a) quererse con un amor situado a años luz por encima del que podían ofrecerse antes de esa donación total. Por el contrario, sin ese "hacerse aptos", la pretensión de obligarse resultaría casi absurda, por desmesurada y prácticamente inalcanzable.

${ }^{8} \mathrm{Al}$ respecto, sostiene Millán-Puelles: «La diferencia entre el entendimiento y las potencias apetitivas humanas se halla en el mismo punto de partida de las correspondientes formaciones. Pretender que entre ambos se conserve un paralelismo riguroso, o una especie de perfecta simetría, sería tanto como desconocer la diferencia entre un poder esencialmente aprehensivo y otro formalmente apetitivo, y no solo esa misma diferencia, sino también la conexión y el orden que hay entre ambos tipos de poderes». Millán-Puelles, Antonio: La formación de la personalidad humana. Madrid: Rialp, 1963 (2ª ed.), p. 162.

${ }^{9}$ In actu exercito o in actu signato, según la terminología medieval. 
de la voluntad sobre sí no es de orden cognoscitivo, justo porque su operación más propia no consiste en percibir sino en amar-querer libremente, con la considerable dosis de sobre-racionalidad y de misterio que semejante acción lleva consigo.

b) Estimo también que, en buena parte por la razón aducida, el desarrollo aristotélico de todo lo pertinente al saber es de mucho más valor y bastante más definitivo que el correspondiente a la voluntad, en el que pueden hallarse incluso déficits de fondo. Y como - se quiera o no, con conciencia o sin ella- Aristóteles ha sido punto de referencia más o menos inmediato de buena parte de la especulación occidental, la comprensión del entendimiento ha seguido por lo común llevando la delantera respecto a la de la voluntad e incluso haciendo más problemático o falseando el conocimiento de esta. ${ }^{10}$

Por ambas causas, y como medio casi nunca consciente para cubrir su "ignorada ignorancia" y la dificultad del empeño, bastantes de los estudiosos de la voluntad han utilizado el expediente, tan cómodo como mistificador, de interpretarla por simetría con lo que se sabe de la inteligencia. Lo cual raramente ha conducido a resultados valiosos.

c) De ahí mi primera observación: al establecer cierto nexo entre el primum cognitum y el hábito generado en el momento de la boda, pretendo solo afirmar que existen algunas semejanzas... y muchas más diferencias.

¿Por qué acudir, entonces, a esta analogía?

Fundamentalmente, para poner de manifiesto el valor inconmensurable que el sí profundo y sincero de la mutua entrega representa en los dominios del amor esponsal. Pues doy por supuesto que quienes me leen aprecian con bastante exactitud la trascendental importancia, para toda la vida humana, de captar la realidad como es en sí -el célebre primum cognitum-, hasta el extremo de que esa aprehensión, y todo lo que por fuerza la acompaña, marca una diferencia abismal, tanto cognoscitiva como operativa, entre el hombre y los restantes animales.

Además, acudo a este símil porque los parecidos entre entendimiento y voluntad justifican tal aproximación, siempre que queden también claras las desemejanzas que los separan; cosa que, por lo demás y según vengo apuntando, es lo propio de la analogía rectamente entendida: similitud, con más acentuada disimilitud.

\footnotetext{
${ }^{10}$ No extraña, por eso, que Ricoeur, justo al inicio del último tercio del siglo XX, se sienta obligado a publicar casi 500 páginas de notable densidad sobre «les rapports entre le Volontaire et l'Involontaire», que no constituyen sino la primera parte «d'un ensemble plus vaste qui porte le titre général de "Philosophie de la Volonté"». Cf. Ricoeur, Paul : Le volontaire et l'involontaire. Paris: Aubier Montagne, 1967, p. 7.
} 


\subsection{Acercamiento inicial al "primum cognitum"}

Aunque de sobras conocido, repito que el primum cognitum - que Zubiri califica como aprehensión primordial de realidad - permite y, en cierto modo, obliga al ser humano a percibir cuanto lo rodea, y a sí mismo, como auténticas realidades, dotadas de una consistencia y un significado propios, que no necesariamente coinciden y nunca se limitan a lo que representan de beneficio o daño para el varón o mujer que las conocen en las distintas vicisitudes de su existencia.

Durante siglos, y con acierto, esta captación de lo real se ha relacionado de forma muy estrecha con lo que el lenguaje común denomina "uso de razón", que señala las distancias entre el niño y el individuo que ya conoce de modo más propiamente humano, lo cual no equivale ni a maduro ni a adulto, entre otras razones porque ese mismo hábito sigue creciendo y perfeccionándose, y coopera al progreso de la persona toda.

\section{Dicho esto, interesa destacar que:}

a) El salto que, sin ninguna conciencia de ello, el niño se ve instado a realizar desde que percibe lo que lo rodea a tenor de sus propias necesidades o antojos, hasta que "aprende a aprehender" los distintos elementos del universo como realidades con caracteres propios, deriva simultáneamente de la excelsitud y de la relativa imperfección o debilidad de nuestro entendimiento. Semejante desarrollo se presenta, pues, como algo impulsado y exigido por la naturaleza humana: es decir, estimulado por su grandeza y requerido por su debilidad. Y, por tanto, siendo del todo imprescindible para el hombre, no es preciso para el ángel ni, muchísimo menos, para Dios.

b) Con lo dicho, no pretendo negar al entendimiento humano la natural capacidad de captar la realidad como es en sí, ya que eso es lo característico de la facultad intelectual, a diferencia de las sensibles. Afirmo más bien que, justo por su índole doblemente participada, nuestro entendimiento no goza en acto de tal aptitud desde el inicio, sino que debe forjarla con el ejercicio progresivamente más perfecto de sí mismo y de los sentidos externos e internos: pues, como requisito básico, estos reclaman cierto nivel de desarrollo ${ }^{11}$ para que la inteligencia pueda llevar a cabo justamente aquella operación que le es más propia, del modo particularmente ele-

\footnotetext{
11 También fisiológico y neuronal, según exponen, entre otros muchos autores, dos científicas contemporáneas: «La lógica de la vida lleva a que la construcción de cada órgano o sistema haga referencia espacial y temporal a la unidad del organismo del que forman parte. Los órganos que funcionan en orden al vivir mismo, como por ejemplo el corazón, se diferencian primero. Sin embargo, lo más específico, lo que permite no solo vivir, sino alcanzar la plenitud de vida que le corresponde como tal viviente, aparece después; y lo que se desarrolla con el vivir más plenamente autónomo madura incluso después del nacimiento. Las manifestaciones vitales superiores, como son las sensitivas, requieren más madurez orgánica. Ese retraso es necesario por la misma naturaleza de las operaciones sensitivas, ya que estas emergen del funcionamiento de un órgano, el cerebro, no solo construido y maduro,
} 
vado que le corresponde... y que nunca alcanza la perfección total: el conocimiento humano puede ser y es de hecho a menudo verdadero y suficiente, y experimenta por lo común un continuo crecimiento extensivo e intensivo. Pero siempre resultará limitado.

c) La capacitación a que aludo se encuentra, por tanto, a favor del entendimiento y viene naturalmente exigida por él. Pero es a la vez fruto de una adquisición, derivada del ejercicio y maduración de las facultades cognoscitivas, cuya razón última reside, por un lado, en la finitud del entendimiento humano, apto-pero-nodel-todo-apto para realizar sus funciones específicas; y, además, en la capacidad de superar su situación inicial, precisamente porque, por su índole espiritual, no queda intrínsecamente condicionado por la materia. ${ }^{12}$

d) Tras diversos estudios, me ha parecido conveniente caracterizar esa posibilidad natural-adquirida del conocer humano como un hábito del entendimiento, fruto del primer acto en el que efectivamente actúa como tal; o, lo que es lo mismo, capta la realidad como es en sí... y no en exclusiva según lo que aquí y ahora supone para quien conoce. ${ }^{13}$

Dejando para un parágrafo posterior lo que se refiere a la condición de hábito, y omitiendo lo que he explicado otras veces, ahora querría llamar la atención sobre una considerable paradoja: el hábito con que el entendimiento se torna capaz de

sino madurado con el uso. Por este motivo, son principalmente epigenéticas». López Moratalla, Natalia - Iraburu Elizalde, María J.: Los quince primeros días de una vida humana. Pamplona: Eunsa, 2004, pp. 44-45.

${ }^{12}$ Muy pertinentes, a este respecto, las puntualizaciones de Basti: «In conclusione, due sono le distinzioni essenziali da tenere presenti per caratterizzare l'operazione cognitiva dei sensi rispetto a quella dell'intelletto. L'operazione intellettiva risulta infatti illimitata rispetto a quella dei sensi in un duplice senso:

1. per il numero potenzialmente infinito di differenze specifiche e di generi che l'intelletto può distinguere, rispetto all'unico genere di differenze ed al conseguente numero finito di specie che ciascun senso può distinguere, derivante dai limiti fisici degli organi di senso;

2. per il fatto che il fine dell'atto intellettivo è di nuovo di capacità potenzialmente infinita, essendo esso il vero intelligibile, ovvero la capacità di un'adeguazione sempre più piena all'essenza dell'oggetto reale e alle sue proprietà, rispetto al fine limitato dell'operazione cognitiva dei sensi che è il soddisfacimento dell'istinto» BAsTI, Gianfranco: Filosofia dell'uomo. Bologna: ESD, 1995, p. 212.

${ }^{13}$ Así lo resumí hace algunos años: «Pero prosigamos con el “hábito de lo real”. En fin de cuentas, este resulta de la primera iluminación intelectual sobre la experiencia sensible, y refleja a la vez e indisolublemente el principio de realidad (el ente es por su ser) y el principio de inteligibilidad (el ente es conocido por su ser); dicho hábito representa la réplica del aspecto más original y elevado de nuestra inteligencia (el intelecto agente) a la manifestación del principio más radical inscrito en las realidades sensibles (su acto de ser); y en esa respuesta a una realidad ontológica en cierto modo inferior a él, el entendimiento humano adquiere su propia mayoría de edad. En efecto, dicho entendimiento, inicialmente en potencia para conocer la realidad en cuanto tal, deviene habitualmente apto para captarla cuando lleva a cabo su primer acto formalmente intelectual; y a partir de ese instante todo lo aprehenderá bajo la razón de realidad, de ente (proceso, si se quiere llamar así, que concuerda con la doctrina aristotélica según la cual los hábitos dianoéticos pueden derivarse de un único acto del sujeto al que perfeccionan)». MeLENDo, Tomás: “La aprehensión originaria del ente y la verdad"; en Sensus communis, Casa Editrice "Leonardo da Vinci", Roma, vol. I, 2000, n. 2, aprile-giugno, pp. 173-174. 
ejercer su función específica es consecuencia de un acto que tal entendimiento no puede realizar antes de haber adquirido el hábito engendrado por ese acto... imposible a su vez sin el hábito que él mismo origina.

Es decir, para hacerse capaz de obrar tal como le conviene por naturaleza, es preciso que inicialmente el entendimiento se sitúe por encima de sí mismo, llevando a cabo una operación para la que aún no está habilitado, sino que más bien lo faculta para realizarla.

Esta especie de aporía, en cuya explicación ejercen un papel de primer orden la sublimidad del acto personal de ser y la del entendimiento agente -manifestación cimera de ese acto en los dominios del conocimiento-, es algo bastante característico del sujeto humano, que, empleando la expresión de Pascal, para alcanzar la grandeza propia del hombre requiere muy a menudo ser más que hombre.

Pero si menciono tal suerte de paradoja, no es tanto para esbozar su solución, sino por la notable luz que puede aportar al estudio de la configuración del que por ahora cabría denominar hábito "correlativo-asimétrico" de la voluntad: el que transforma al varón y la mujer que se casan en esposos: es decir, en personas capaces de comenzar a amarse conyugalmente.

\subsection{La aprehensión primordial de realidad concebida como hábito}

Antes de analizarlo directamente, y aun cuando resulte superfluo, me permito recordar que lo que en filosofía denominamos hábito tiene menos que ver con la repetición de actos que con la transformación y mejora que introduce en quien lo adquiere. Y que apunta, sobre todo, a la potenciación y robustecimiento de la facultad o facultades en las que semejante hábito reside o a las que armoniza, ${ }^{14}$ aptas ahora para llevar a término operaciones para las que antes solo se encontraban en potencia remota. ${ }^{15}$

\footnotetext{
${ }^{14}$ La conveniencia del uso del plural queda subrayada en esta cita de Possenti, redactada en otro contexto y con otros fines: «L'esito è meglio assicurato quanto più il filosofare credente ha cercato di mantenersi fedele ad una notevole regola, cioè l'intercomunicazione vitale, la continuità e il sostegno tra gli habitus, per cui quelli superiori sostengono, fortificano e affinano quelli inferiori. Ciò significa che l'habitus teologico e la contemplazione evangelica spiritualizzano e possono rendere maggiormente acuto l'habitus metafisico. L'enciclica Aeterni Patris (1879) col suo stile antico conferma questa regola: “E tanto poco vero che la luce sopraggiunta della fede estingua o diminuisca il vigore dell'intelligenza, che anzi piuttosto lo perfeziona, e accrescendone le forze lo rende capace di cose maggiori e più alte di quelle a cui è naturalmente ordinato". Pertanto la "filosofia cristiana" rimane filosofia, ossia qualcosa di mondano, ma è posta in una condizione migliore: è filosofia che raggiunge la maturità, che procede quanto più si può nella conoscenza della verità dell'essere». Possentı, Vittorio: Filosofia e rivelazione. Roma: Città Nuova, 2000 (2 $2^{\underline{a}}$ ed.), p. 41.

${ }^{15}$ Por ahí camina la captación de la belleza como síntesis superadora de los trascendentales.
} 
a) De hecho, como acabo de sugerir, el hábito de que vengo hablando técnicamente, según la distinción clásica, se situaría entre los "dianoéticos". No obstante, lo considero fruto de un solo acto, aunque vaya precedido de un sinfín de operaciones cognoscitivas, que provocan la posibilidad de llevar a cabo con éxito ese-único-actoque-origina-el-hábito.

Desde este punto de vista, el acto constituiría más bien una especie de detonante que cataliza, aúna y potencia cuanto anteriormente se ha llevado a cabo en la línea de la perfección que va a provocar, pero que, en efecto, compone la causa propia e inmediata del crecimiento experimentado, a modo de salto cualitativo, por la potencia o potencias en juego.

b) Como también he repetido, semejante hábito está a favor de nuestra inteligencia, y del hombre en cuanto tal, por lo que surge naturalmente cuando el conjunto de las facultades cognoscitivas adquiere la exigida sazón, sin que en ello haya una peculiar o específica y expresa intervención de la voluntad, y mucho menos una acción libre y consciente tendente a producirlo.

c) Igual que los restantes, una vez creado, este hábito puede y debe crecer con su ejercicio (o, mejor, con el de la facultad correspondiente enriquecida por él y, en suma, con el de la persona entera), tanto desde el punto de vista de la extensión como, sobre todo, en lo que atañe a su intensidad.

Lo cual quiere decir que, de forma natural, mientras no realice actos contrarios a él, todo ser humano va multiplicando el número de realidades que conoce como tales, e incrementando su capacidad de distinguir entre lo que es o no es real y, más todavía, entre los diversos modos de serlo: realidad katà physin o con existencia extramental frente a la meramente pensada, imaginada o anhelada, realidades hasta cierto punto y en cierta medida autónomas - substancias- o inherentes en otra -accidentes-, artificiales o naturales, y un largo etcétera.

Y, además, que esa persona acrecienta el sentido de lo real, marcando la distancia casi insalvable entre los distintos tipos de entes $\mathrm{y}$, más que nada:

$\left.c^{\prime}\right)$ Concediendo toda la importancia que merece a la pregunta a menudo formulada como: "pero eso, ¿existe o no existe?", y a la respuesta que reclama por nuestra parte; pues, en caso de existir, nos exigiría un modo de obrar proporcionado. ${ }^{16}$

\footnotetext{
${ }^{16}$ Es este uno de los sentidos más hondos de la responsabilidad humana, de estricta raigambre metafísica: la capacidad de conocer la realidad tal como es, y en particular, a las demás personas, obliga a cada varón o mujer a responder, actuando en función de lo que tal realidad reclama.

Así lo expone Ratzinger: «Die Frage nach dem Ethos steht auf der Tagesordnung unserer Zeit, mit großer Dringlichkeit. Der Glaube an den Logos, das Wort am Anfang, versteht Ethos als Ver-antwortung, als Antwort auf das Wort und gibt ihm seine Rationalität wie seine wesentliche Richtung». RATzINGER, Joseph: Einführung in
} 
$\left.c^{\prime \prime}\right)$ Y dando mayor relieve a lo que cada cosa es en sí misma que a lo que representa para uno: utilidad, otras ventajas o satisfacciones, contrariedades, daños, esfuerzo, etc.

En la perspectiva del metafísico, cuya tarea en cierto modo consiste en tematizar el hábito a que nos referimos para advertir todo cuanto hay en el universo en su condición de ente - esto es, en cuanto ejerce de modos y con intensidades distintos el correspondiente acto de ser-, esa maduración extensiva e intensiva se traduce en el hecho de que, al considerar intelectualmente lo que el ente engloba o encarna, tal conocimiento se va cargando más y más de realidades significativas.

Por eso comento a mis alumnos que toda la metafísica podría resumirse en una afirmación del estilo "el ente es", con la peculiaridad de que, al considerarla en los tiempos de formación, goza de un sentido, una amplitud y una densidad muy pobres, mientras que el paso de los años y el ejercicio continuado de la reflexión vital y filosófica la van dotando de un contenido cada vez más vasto e intenso. Hasta el punto de que en ella (en el hábito tematizado) se compendia todo lo que quien se dedica a estas tareas sabe de la realidad y, como apuntaba, el bosquejo de la respuesta que, ante cada uno de esos elementos reales, esa persona debe llevar a cabo: conocerlo más o menos (verum), apoyarlo o intentar que desaparezca (bonum), contemplarlo con fruición y embellecerlo más todavía (pulchrum)...

Si este engrandecimiento-intensificación no se produjera, me temo que la labor metafísica - condensada toda en el habitus entitatis - podría considerarse casi nulad) En principio, justo por su carácter natural, el hábito del que estoy hablando resulta muy difícil, casi imposible o, según algunos, incluso imposible de perder. Lo que equivale a sostener que, en situaciones normales, el ser humano tiende a percibir la realidad tal como es, aunque nunca de manera absolutamente perfecta ni exhaustiva, y con las interferencias generadas por el yo y el aditamento de bastantes errores, derivados de causas muy diversas.

das Christentum: Vorlesungen über das Apostolische Glaubensbekenntnis. Bonn-Münster und Tübingen: Meinen Hören, 9. Aufl., 2007 (1. Aufl., Kösel-Verlag, 1968), SS. 24-25: Vorwort zur Neuausgabe 2000.

La misma idea ha sido también ampliamente desarrollada por la logoterapia. Así la resume Fizzotti: «Se la vita è intesa come un compito da realizzare ed al quale è necessario dare delle risposte (Antwort), questo può avvenire solamente mediante un pegno a dare la risposta giusta, a essere pienamente responsabile (ver-antwortlich). È indicativa, in proposito, l'espressione di Frankl: "Ë la vita stessa a porre la domanda. L'uomo non ha nulla da chiedere; è piuttosto lui stesso l'interrogato, colui che deve rispondere alla vita, di cui è responsabile" (Logoterapia e analisi esistenziale, p. 97)». Fizzotтı, Eugenio: Logoterapia per tutti: Guida teorica-practica per chi cerca il senso della vita. Soveria Mannelli: Rubbettino, 2002, p. 85.

Para el propio Frankl se trata de una doctrina clave y reiterada a lo largo de todos sus escritos. A modo de ejemplo: «Ultimately, man should not ask what the meaning of his life is but rather he must recognize that it is he who is asked. In a word, each man is questioned by life; and he can only answer to life by answering for his own life; to life he can only respond by being responsible. Thus, logotherapy sees in responsibleness the very essence of human existence». FrankL, Viktor: Man's Search for Meaning. New York: Pocket Books, 1988 (4th ed.), p. 130. 
Sin embargo, las circunstancias de la civilización actual, genéricamente conocida como moderna y postmoderna, pueden provocar que el hábito en cuestión se debilite en extremo, que desaparezca o incluso que no llegue a forjarse.

\subsection{La primacía del yo... en detrimento de la realidad}

Como se trata de un asunto delicado, objeto de múltiples polémicas en los últimos decenios, ${ }^{17}$ me detengo unos momentos a considerarlo.

\subsubsection{En el ámbito cognoscitivo}

Tal vez la forma más sencilla de hacerlo sea apelar al subjetivismo o relativismo que aquejan a la sociedad de hoy, y que muy pocos entre los intelectuales serios, y entre las personas dotadas de sentido común y rectitud de vida, se resisten a admitir.

Pues bien, sin entrar de momento en sus causas, el relativismo fuerte y profundamente arraigado no sería sino:

a) La imposibilidad de reconocer lo real en cuanto real o tal como es en sí, para advertirlo exclusivamente según el valor que tiene para-mí o, lo que es lo mismo, el que yo le otorgo en función de mi estado del momento y de lo que me rodea e influye en tal estado.

b) Más la pretensión, sostenida con absoluta y contradictoria firmeza, ${ }^{18}$ de que a las restantes personas les sucede lo mismo.

Bajo semejante prisma, la expresión técnica "el ente en cuanto ente", rectamente considerada, viene a equivaler a la de "el otro (o el ente) en cuanto otro" y no como prótesis o prolongación de mi yo: de mi interés, de mis deseos, de mis egoísmos, de mis gustos y preferencias, de mis fobias o manías, del conjunto de mis circunstancias.

\footnotetext{
${ }^{17}$ A este respecto, es clásico el libro de CARDona, Carlos: Metafísica de la opción intelectual. Madrid: Rialp, 2 $2^{\mathrm{a}}$ ed., 1973. También cabe consultar Melendo, Tomás: Entre moderno y postmoderno, Servicio de Publicaciones de la Universidad de Navarra, Pamplona, 1997.

${ }^{18}$ Ese carácter contradictorio, y no sólo aporético, se encuentra bien subrayado por Jonas, en relación con el solipsismo, fácilmente identificable con el relativismo extremo: «Außer einem Wahnsinnigen natürlich hat nie jemand den Solipsismus ernst gemeint: für ihn argumentieren, außer im Selbstgespräch, heißt, „den Anderen“ anerkennen, dessen Zustimmung gesucht wird. Das Argument ist dann frivol aua Dialog, während der absolute Monolog das Vorrecht des Verrückten ist. Keiner von beiden kann Anspruch auf die Tugend kritischer Strenge machen, mit der der Solipsismus seine Sache empfiehlt». Jonas, Hans: Das Prinzip Leben: Ansätze zu einer philosophischen Biologie. Frankfurt am Main und Leipzig: Suhrkamp, 1997, SS. 63-64.
} 
De esta suerte, en la medida en que el relativismo impere en una vida, queda excluido de ella el conocimiento de lo real como tal: de lo que es en cuanto que es. Y como la cultura actual empuja bastante en la dirección del subjetivismo relativista, no debería causar excesiva extrañeza la afirmación de que el hábito que permite conocer la realidad como "lo que es en si" pueda atenuarse, ser excluido o incluso no llegar a cobrar vida.

Lo cual no es hacedero sin la creación de un hábito contrario -y enfrentado también a la natural apertura del entendimiento al ser-, que compita con el de "la aprehensión primordial de realidad" y lo sustituya por una suerte de "atención prioritaria o exclusiva al yo", como puede comprobarse con solo dar un repaso a buena parte de las estructuras más propias de la civilización actual y a los comportamientos también más caracterizadores de bastantes de los individuos que la componemos.

\subsubsection{En los dominios afectivo-volitivos}

Sin descender a excesivos detalles, estimo conveniente afirmar que en el surgimiento de este contra-hábito "opuesto" sí que es precisa la intervención más o menos consciente de la voluntad, que, por motivos muy varios y en los que no deseo detenerme, desvía al entendimiento de su natural orientación.

Así expone Cardona, con palabras de Søren Kierkegaard, uno de los aspectos de este posible proceso:

El conocimiento intelectual posibilita el acto de libertad, pero evidentemente no lo constituye: dejaría de ser libre ese acto si estuviese determinado por su contenido una vez aprehendido. "Por tanto, si un hombre, en el mismo momento en que ha conocido el bien, no lo hace, entonces se debilita el fuego del conocimiento. Además, está el problema de lo que la voluntad piensa de lo que se ha conocido. La voluntad es un principio dialéctico y tiene bajo sí toda la actividad del hombre. Si no le gusta lo que el hombre ha conocido, no resulta ciertamente que la voluntad se ponga a hacer enseguida lo contrario de lo que dice la inteligencia: oposiciones tan fuertes son ciertamente muy raras. Pero la voluntad deja pasar un poco de tiempo: jesperemos hasta mañana, a ver cómo se ponen las cosas! Entre tanto la inteligencia se oscurece cada vez más, y los instintos más bajos toman cada vez más la delantera. Ay, el bien hay que hacerlo enseguida, apenas conocido (he aquí la razón por la que en la pura idealidad el paso del pensar al ser se da con tanta facilidad, porque ahí todo se hace enseguida); pero la fuerza 
de la naturaleza inferior consiste en dilatar las cosas. Cuando de este modo el conocimiento ha llegado a ser bastante oscuro, entonces la inteligencia y la voluntad ya pueden entenderse mejor; finalmente están ya completamente de acuerdo, porque la inteligencia se ha puesto ya en el lugar de la voluntad, y reconoce así que es perfectamente justo lo que la voluntad quiere". ${ }^{19}$

En concreto, simplificando un tanto y sin pronunciarme sobre la cualificación moral del hecho:

a) Un niño cultural y educativamente habituado a interpretar cuanto lo rodea en función de sí mismo, de sus caprichos y pretensiones o de sus antojos y desganas, ejerce una fuerte oposición para que vea la luz el primum cognitum, que completa la capacidad de su entendimiento. Pues semejante hábito le obligaría a conocer el mundo tal como es, a responder a las exigencias que este le impone y - por decirlo con pocas palabras - a prescindir o poner entre paréntesis los requerimientos de su yo: en resumidas cuentas, su propio estado de ánimo y aquello que le pide la situación concreta en que se halla y que en muchos casos, por el esfuerzo que implica, no está dispuesto a realizar. En tales circunstancias, en las que el yo ocupa el centro del universo, al menos no es imposible que el habitus entitatis, si alcanza a cuajar, resulte mínimamente operativo.

b) Y, con las mil variaciones y matices propios de cada existencia particular, algo muy semejante cabría sostener del joven o del adulto que, acostumbrado inicialmente a guiarse por el bien del otro o de lo otro (de la realidad en cuanto tal), reoriente su vida progresivamente - mejor, regresivamente-, y comience a prestar más y más

${ }^{19}$ Cardona, Carlos: Metafísica del bien y del mal. Pamplona: Eunsa, 1987, p. 115. El texto de Kierkegaard corresponde a La enfermedad mortal. Cardona utiliza la traducción italiana, llevada a cabo por Fabro; en Opere. Florencia: Sansoni, 1972, p. 671.

El original, en su contexto, dice así: «I Aands-Livet er der ingen Stilstand (egentlig heller ingen Tilstand, Alt er Actualitet); dersom altsaa et Menneske ikke i samme Secund, som han har erkjendt det Rette, gjør det - ja saa gaaer nu for det første Erkjendelsen af Kog. Og dernæst saa bliver Spørgsmaalet, hvad synes Villien om det Erkjendte. Villien er et Dialektisk, og har igjen under sig hele den lavere Natur i Mennesket. Synes denne nu ikke om det Erkjendte, saa følger deraf vel ikke, at Villien gaaer hen og gjør det Modsatte af hvad Erkjendelsen forstod, saa stærke Modsætninger forekomme vistnok sjeldnere; men saa lader Villien nogen Tid gage hen, det bliver et Interim, det hedder: vi vil dog see det an til imorgen. Under alt Dette bliver Erkjendelsen dunklere og dunklere, og det Lavere seirer mere og mere; ak, thi det Gode maa gjøres strax, strax idet det er erkjendt (og derfor gaaer det i den rene Idealitet saa let med Overgangen fra at tænke til at være, thi der er Alt strax), men det Lavere har sin Styrke i at trække ud. Saa smaat har Villien ikke noget mod, at dette skeer, den seer næsten igjennem Fingre dermed. Og naar saa Erkjendelsen er blevet behørig dunkel, saa kan Erkjendelsen og Villien bedre forstaae hinanden; tilsidst samtykke de ganske, thi nu er Erkjendelsen gaaet over paa Villiens Side, og erkjender, at det er ganske rigtigt som den vil det. Og saaledes lever maaskee en stor Mængde Mennesker; de arbejde saa smaat paa at fordunkle deres ethiske og ethisk-religieuse Erkjenden, der vil føre dem ud j Afgjørelser og Conseqventser, som det Lavere i dem ikke elsker; derimod udvide de deres æsthetiske og methaphysiske Erkjenden, hvilket, ethisk, er Adspredelse». KierkegaArd, Søren: Sygdommen til Døden: En christelig psychologisk Udvikling til Opbyggelse og Opvakkelse. En Samlede Værker, udg. af A. B. Drachmann, J. L. Heiberg og H. O. Lange, gennemset af Peter P. Rohde; 3. Udg. 1-20. Gyldendal, København: 1963, Bind 15, S. 146-147. 
excluyente atención a su propio beneficio e intereses: bienestar individualista, protagonismo, prestigio profesional, ambición de dinero, prepotencia, orgullo, placer...

Como anticipaba, en este caso "la aprehensión primordial de realidad" y el hábito en que consiste pueden verse aminorados, o incluso suplantados, por "la aprehensión primordial, exclusiva y contranaturalmente privilegiada, del propio yo", es decir, si llega a constituirse, por el hábito que inclina a actuar solo en dependencia de ese ego y a prescindir de todo lo demás.

\section{Sustancialmente, sin excesivos tecnicismos, parece afirmarlo Benedicto XVI:}

En la actualidad, un obstáculo particularmente insidioso para la obra educativa es la masiva presencia, en nuestra sociedad y cultura, del relativismo, que, al no reconocer nada como definitivo, deja como última medida solo el propio yo con sus caprichos; y, bajo la apariencia de la libertad, se transforma para cada uno en una prisión, porque separa al uno del otro, dejando a cada cual encerrado dentro de su propio " $\mathrm{yo}^{\text {". }}{ }^{20}$

\section{El "primum" en los dominios de la voluntad}

Estimo que estos datos son suficientes para abordar con alguna posibilidad de éxito un primer análisis, no exhaustivo, del hábito que capacita para comenzar a amar conyugalmente: una virtud que cabría denominar - con expresión que me gustaría mejorar, pero para la que de momento no encuentro sustituto- el habitus sponsalis amoris. ${ }^{21}$

Antepondré, sin embargo, la consideración de ciertas cuestiones previas y fundamentales, que apelan a un hábito análogo, también de la voluntad, pero anterior en el tiempo y mucho más decisivo, por cuanto marca el "tono" característico de todos los actos que esta facultad ejerce.

Inicio con una simple descripción.

20 «Oggi un ostacolo particolarmente insidioso all'opera educativa è costituito dalla massiccia presenza, nella nostra società e cultura, di quel relativismo che, non riconoscendo nulla come definitivo, lascia come ultima misura solo il proprio io con le sue voglie, e sotto l'apparenza della libertà diventa per ciascuno una prigione, perché separa l'uno dall'altro, rendendo ciascuno a ritrovarsi chiuso dentro il proprio "io». BenEDicto XVI: "Discurso en la Ceremonia de apertura de la Asamblea eclesial de la Diócesis de Roma sobre 'Familia y comunidad cristiana: formación de la persona y transmisión de la fe' (6 de junio de 2005)", Acta Apostolicae Sedis, An. et vol. xcviI, 1 Iulii 2005, n. 7, p. 816; trad. cast. en El Papa con las familias. Madrid: BAC Popular, 2006, pp. 11 y 12.

Se trata de una idea recurrente en el Sumo Pontífice ya desde bastante antes de su consagración como Papa. Por ejemplo, en la "Homilía pronunciada durante la Santa Misa 'para elegir al Pontífice'", el 18 de abril de 2005, en la Basílica de San Pedro, recoge casi literalmente el mismo juicio: «Si va costituendo una dittatura del relativismo che non riconosce nulla come definitivo e che lascia come ultima misura solo il proprio io e le sue voglie». RAtzinger, Joseph: Acta Apostolicae Sedis, An. et vol. xcviı, 7 Maii 2005, n. 5, p. 687.

${ }^{21}$ En una nota posterior, lo identificaré con la virtud de la castidad conyugal. De momento, no es fácil advertir esa correspondencia. 


\subsection{Mucho antes de la boda}

En circunstancias normales e incluso óptimas, dos personas dispuestas a casarse se dispensan ya un amor recíproco, que es justo el que les lleva a pensar en el matrimonio.

Y aquí aparece la desemejanza inicial y tal vez más de fondo entre el primum cognitum y el hábito - primordialmente voluntario- al que ahora empiezo a referirme.

Pues, como vimos y enseguida ampliaré, "la aprehensión primordial de realidad" establece una radical diferencia en los dominios del conocimiento. Al contrario, la capacitación originada por el sí matrimonial se mueve ya, o al menos puede y debería moverse, en la esfera del amor auténtico, al que en ese mismo instante hace madurar y crecer de manera en verdad asombrosa. Por eso, aunque el influjo de este nuevo hábito sea muy notable -e indispensable para los esposos-, no instaura en el ejercicio de la voluntad un salto cualitativo idéntico o comparable al que adviene a la inteligencia con el uso de razón.

Me explico. Considerando el asunto con todo rigor, cabría sostener que con la adquisición del habitus entitatis se entra por primera vez en la esfera propia del conocimiento en su acepción más estricta: pues si aprehendo la realidad como no es, sino en función de mis circunstancias y como simple estímulo para mi obrar, difícilmente puedo afirmar que la conozco.

Hablando de nuevo en tono mayor, estamos ante la diferencia que existe entre el (todavía) no y el (ya) sí: traducible, si atendemos al fondo último de la cuestión y extremamos la rigidez de las expresiones, en un directo "no conozco", frente al "sí conozco".

Sin duda, esta tesis resulta demasiado fuerte, por lo que requiere ser matizada.

Y, en efecto, como en todas las realidades que se consideran desde la perspectiva metafísica, muy similar a la de la vida ordinaria, tal vez la palabra clave sea "depen$\mathrm{de}^{\prime \prime}$. ¿De qué? De las exigencias que establezcas para aquello que aspiras a enjuiciar o calificar.

\subsubsection{Un ejemplo un tanto difícil}

En filosofía, uno de los ejemplos más claros, aunque no sencillo de captar sin ciertos conocimientos previos, es el entero camino recorrido por Aristóteles para determinar el tema propio (o el menos impropio, el más propio o el absolutamente propio) de la filosofía primera: el ente. 
Tras afirmar que lo que después llamaríamos metafísica estudia todo lo que es, Aristóteles elimina de su ámbito al más tarde denominado ens per accidens o por concomitancia o coincidencial, y al ente "lógico", que - en cuanto tal- tiene su residencia en el lógos humano.

A continuación declara que el ente en su sentido más preciso es, por el momento, la ousía, relegando los accidentes a los dominios de lo que, en estricto rigor, casi no es.

Pero de inmediato se replantea la cuestión, de forma que lo que ahora merece tout court el calificativo de ente son las formas separadas y no las sustancias compuestas de materia y forma.

Y no todo acaba ahí. Tensando el arco hasta el máximo admitido por su comprensión (superada por otros filósofos), Aristóteles declara que la única realidad merecedora de la atención de la filosofía primera es Dios, Ousía por excelencia, Enérgeia o Acto puro, Pensamiento de su propio Pensamiento. La filosofía primera es Teología, contemplación de Dios.

No obstante, frente a las pretensiones de Jaeger y sus discípulos, ${ }^{22}$ nada de esto implica una modificación sustantiva de la doctrina aristotélica al respecto, sino más bien un cambio progresivo de perspectiva o, mejor aún, una mayor exigencia a la hora de determinar aquello que debe - prioritaria, pero no exclusivamente- considerar la metafísica: lo que es (el ente), en su acepción más noble y estricta.

De modo que, en justicia, incluso lo coincidencial y lo lógico caen bajo la mirada del metafísico, aunque no sea más que para dejar neta y clara constancia de su existencia... y de que la filosofía primera no debe hacer más que eso: dejar bien sentado que lo hay. ${ }^{23}$

En resumen y a través de un ejemplo: cuando a un metafísico se le pregunte si el accidente es ente o si lo es el simple ente coincidencial, habrá de responder con el decepcionante "depende", para después establecer las distinciones oportunas. Cada uno de ellos se sitúa dentro del ente en un distinto grado de propiedad: si aceptas o te colocas en ese nivel, la respuesta será afirmativa (es ente), pero si reclamas una mayor densidad en la encarnación o ejercicio del ser, la denominación propia de

\footnotetext{
${ }^{22}$ Estamos ante un asunto de sobras conocido. Para una puesta a punto relativamente reciente, me permito remitir a Melendo, Tomás: La metafísica de Aristóteles. Método y temas (I), Cuadernos de Anuario Filosófico, Servicio de Publicaciones de la Universidad de Navarra, 1997, pp. 5-17.

${ }^{23}$ No es algo sin importancia, sino todo lo contrario: puesto que sin admitir la existencia de lo coincidencial, cuyo rechazo era la ambición máxima de Hegel y de todo racionalismo extremo, y de lo que se da en nuestra mente, tanto en los dominios del conocimiento como en el de los apetitos y de la afectividad, resulta imposible comprender el mundo real tal como en efecto es y actuar en consecuencia.
} 
ente comenzará con las substancias, con las substancias separadas... o, en la perspectiva aristotélica más madura, se limitará a Dios. ${ }^{24}$

\subsubsection{Una realidad más cercana}

Y, cuando la cuestión versara sobre si los animales conocen o no, la respuesta inicial sería - como ya apunté- un sí relativamente nítido. Aunque, dando un giro de tuerca a lo que más estrictamente significa conocer, cabría aclarar que los animales no lo hacen, puesto que su conocer no es sustantivo, sino - como asimismo sugerí- un mero requisito para obrar de un modo u otro, y que la realidad que perciben resulta por completo condicionada y minimizada en función de su carga instintiva; que solo advierten lo que les resulta beneficioso o dañino y en cuanto beneficioso o dañino: no tal como es en sí -y, en este sentido, no lo conocen-, sino exclusivamente para obrar en consecuencia, en función de su relación con las circunstancias actuales de cada animal. ${ }^{25}$

Tras estos esclarecimientos, tal vez se entienda mejor por qué y cómo, hasta que cada sujeto humano establece su propio "habitus entitatis", no cabe hablar de un auténtico conocer.

Por el contrario, antes de comenzar la gran aventura del matrimonio - con el sí de la boda-, los futuros cónyuges pueden efectivamente amar a los otros y amarse entre sí con un tipo de amor que, ciertamente, no tendrá la fuerza y las característica

\footnotetext{
${ }^{24}$ En semejante sentido, en cuanto estructuralmente Dios (no) es para Aristóteles (sino) el Primero de los Entes, el filósofo griego podría caer - a pesar de su grandeza especulativa- bajo la acusación de onto-teo-logía que Heidegger, sin razón, lanza contra toda la metafísica occidental.

${ }^{25}$ Como explica Polo: «Si lo vemos biológicamente, la primera caracterización de la vida intelectual es la suspensión de la acción práctica por otro tipo de actividad que se caracteriza precisamente porque es capaz de llegar a objetos universales o a ideas generales, a considerar consistencias, como el que el "agua es agua"». Polo, Leonardo: Ética. México: Universidad Panamericana, 1993, p. 63.

Y, ampliando la misma idea: «Ahora bien, en la vida del hombre existe la pausa por excelencia: es el pensamiento. Dicho escuetamente, pensar significa pararse a pensar. Por eso, pensar es también la permanencia segura, el habitar cabe sí, mientras que la indigencia equivale a estar a la intemperie. El pensamiento posee una riqueza de recursos que supera el necesitar. De aquí que su unión con penia [...] comporte para Platón una apertura superior a la satisfacción sensible. Esta apertura, este camino libre, es el estatuto de la filosofía platónica. Por su parte, Aristóteles define al hombre como animal dotado de logos. Con esto quiere decir que el hombre es el único animal que alcanza su propia vida cobrándola y dirigiéndola. El hombre se adentra en su vida encontrándola, haciéndola efectivamente suya en su inteligencia, y gobernándola con ella. Lo específicamente humano consiste en que el alma puede ser recogida por una actividad que surge de ella misma y en la cual íntimamente está consigo y se abre a todas las cosas. Pausa, demora, íntimo habitar y poseer, señalan la radical superioridad de un vivir autónomo, que no se cifra en una indigencia intolerada; ignorarlo da lugar a un vicio denominado crematística. Aristóteles no niega con esto que el hombre padezca necesidades, pero no lo define por necesitar, pues también el hombre se tiene a sí mismo en la pausa abierta, en el desconfinamiento de su individualidad». Polo, Leonardo: La persona humana y su crecimiento. Pamplona: Eunsa, 1996, p. 81.
} 
peculiares del amor conyugal, pero que no por ello debería ser excluido de la esfera del amor cabal y genuino.

Desde semejante perspectiva, que considero correcta, lo realmente similar al primum cognitum auténtico ${ }^{26}$ es la elección primordial por la que el ser humano, llegado al "uso de voluntad" - o, más bien, al "uso de libertad", utilizando una expresión que ignoro si ha sido empleada hasta hoy, pero tal vez válida-, opta, con más o menos conciencia, pero de forma resolutiva, entre:

a) Ponerse a sí mismo como razón y referencia de todo querer.

b) O bien otorgar ese puesto a la realidad en cuanto tal y, en fin de cuentas, a Dios, al que esa realidad - entendida como tal, como otra respecto al yo- por fuerza remite, aunque no sin un proceso argumentativo por nuestra parte.

Sobre este extremo querría detenerme.

\section{Del "primum volitum" al "primum electum"}

\subsection{La opción primordial en el ámbito volitivo}

Estamos, también ahora, ante un tema que he estudiado en otros lugares, y objeto a su vez de no pocas controversias. En su fondo late una dualidad, no por todos aceptada, al menos en la integridad de sus consecuencias: relacionada a su vez con la clásica distinción entre voluntas ut natura y voluntas ut ratio, se trata de la diferencia que media entre el amor natural y el amor electivo. ${ }^{27}$ Este segundo tipo de amor, conocido también como dilección, es el propiamente humano, fruto de la libertad, y el que prioritariamente consideraré en lo que sigue.

\footnotetext{
${ }^{26}$ Más adelante explicaré la necesidad de este $\mathrm{u}$ otro adjetivo análogo para caracterizar al primum cognitum. Advierto de momento que mediante él quiero referirme al hábito que efectivamente perfecciona la inteligencia y lleva a conocer la realidad como es en sí misma, y no al contra-hábito que conduciría a percibirla en función de los propios deseos o circunstancias (tal como resulta para-mí).

${ }^{27}$ Con palabras de Scola: «Voluntas ut natura es una extensión del concepto de voluntad realizada por Tomás para expresar la existencia en el hombre de un sistema de inclinaciones, dentro del cual se coloca también el amor naturalis como expresión de la estructura afectiva elemental del sujeto, que se da al hombre por naturaleza, aun antes de que él lo elija. Las consecuencias de tal afirmación son tan importantes que su olvido ha propiciado, como ha mostrado Pinckaers, esa involución de la moral clásica que es la moral casuística moderna. Esta ha nacido a partir de la convicción de que la voluntad como apetito racional sería indiferente hacia su objeto. Nada más falso. De todo lo dicho se puede deducir que la voluntad está de hecho inclinada siempre al propio bien porque originalmente, espontáneamente según el modo como está hecha, es decir naturalmente, o mejor creaturalmente, el hombre está inclinado al bien. Su posibilidad de elegir, que es lo que le hace propiamente hombre - queda claro- no se ejerce sobre una tabla rasa, sino sobre una inclinación concreta al bien». Scola, Angelo: Identidad y diferencia. Madrid: Ediciones Encuentro, 1983, pp. 22-23.
} 
En los dominios del bien, el surgir de este género de amor podría considerarse análogo, nunca igual, al auténtico o genuino primum cognitum. Precedido de la preparación imprescindible, similar a la que se lleva a cabo en la esfera cognoscitiva, sería el fruto directo e inmediato de la opción por el bien en sí que a toda persona no "viciada contraculturalmente" 28 se le propone de forma natural cuando, como decía, alcanza el "uso de libertad", estrechamente relacionado con el de razón. ${ }^{29}$

Antes o al margen de semejante elección, lo que existe en el hombre - de manera análoga a las restantes realidades, y en particular a los animales brutos- es un amor meramente natural, aunque en absoluto despreciable o no digno de consideración, cuyo fundamento es la semejanza de lo amado con uno mismo. Con un amor de estas características quieren las leonas a sus cachorros, la oveja a sus corderillos... el padre y la madre humanos a sus hijos, estos a sus padres y a sus hermanos, cualquier persona a aquellas otras que $a$ ella le caen simpáticas, y un largo etcétera.

Si alguna vez pudiera darse aislado, cosa que resulta casi imposible, el punto terminal de referencia de este género de amor sería, con los matices del caso, uno mismo, el propio yo: lo que, en el ámbito de lo finito, goza de mayor identidadafinidad conmigo.

Son pertinentes al respecto, aunque resulten un tanto arduas, las siguientes consideraciones:

En su monumental obra Los actos del amor, Kierkegaard afirma que lo característico del amor cristiano, a diferencia del "amor profano" es que allí la "determinación intermedia" es Dios mismo. Radicalmente, si no amo por Dios, amo por mí; y entonces la cualidad intermedia es la "preferencia": amo a los demás en cuanto se me asemejan, en cuanto participan de mí, en cuanto me placen. Sin embargo, hay que decir que aquella característica del amor cristiano es igualmente propia del recto amor humano sin más, del que la caridad sobrenatural es sanación, perfección y elevación, y no negación. También aquí si el amor decisivo es a Dios, en él caben los otros amores: el amor a las otras personas - en cuanto amadas por Dios - y el amor a mí mismo, con idéntico fundamento. Fuera de ese amor, el amor a otra persona $-\mathrm{e}$ incluso el amor propio $-{ }^{30}$ es siempre precario, como precario es el ente sin el Ser: carece de una razón

\footnotetext{
${ }^{28}$ Como bien explica Cardona, la opción opuesta es resultado de una clara violencia: «Para optar mal hay que hacerse violencia: violencia a los primeros principios universales conocidos por la luz de la razón natural, muy empleados hasta entonces; y violencia a la rectitud tendencial de la voluntad ordenada al bien de la razón». CARDonA, Carlos: Metafísica de la opción intelectual, cit., p. 150.

${ }^{29}$ De nuevo, sostiene Cardona: «Se pasa del estadio animal al espiritual por un acto decisivo de libertad, que cualifica éticamente los actos sucesivos. Ya he dicho que esto se produce en el momento en que el niño adquiere uso de razón. Pero la vida del hombre se distiende en decurso temporal. Y aquella opción ética debe corroborarse, ratificarse (o rectificarse, mediante una "conversión", si la opción fue mala): es decir, debe transformarse en un hábito, en una disposición estable y difícilmente removible». CARdona, Carlos: Ética del quehacer educativo. Madrid: Rialp, 2ª ed., 2001, p. 99.

${ }^{30}$ Aunque no puedo detenerme en este punto, lo estimo realmente crucial para explicar buena parte del drama de la civilización contemporánea. Los amores cuyo fundamento último es un yo finito resultan, por naturaleza e inevitablemente, deficitarios.
} 
verdaderamente última, de sólido asiento. Y así está expuesto a la frustración: en cuanto que solo Dios, infinita y eternamente amable, adecua mi capacidad ilimitada de amar; y en cuanto que solo Dios me garantiza la plena correspondencia que mi amor necesita. La entrega de mi yo - el amor es darse y disolverse en el amado- solo se justifica plenamente en el Tú divino, que es el Yo absoluto. En el Tú infinito de Dios es donde se fundamenta decisivamente la amorosa pérdida de mi yo. ${ }^{31}$

\section{Apunto aquí, aunque tal vez no fuera necesario, que:}

a) El disolverse en el amado, del que habla Cardona, es solo una metáfora más o menos acertada, pero con sentido: aunque en absoluto niega la individualidad del sujeto amante, pretende sostener que sólo ama de veras quien sabe olvidarse de sí mismo y atender seriamente al bien ajeno: la paradoja, que muchas veces he intentado explicar, es que solo mediante ese olvidarse uno se gana radicalmente y crece, o que la persona únicamente logra vivirse en plenitud cuando se des-vive. ${ }^{32}$

b) A lo que habría que añadir, pero asimismo como un simple apunte, que la cuestión es mucho más radical y verdadera si consideramos la relación del hombre con Dios: puesto que su Ser infinito contiene de manera inefable pero real, no solo la plenitud de cuanto yo soy, mi mejor identidad ${ }^{33}$ (de suerte que en Él es donde alcanzo a ser lo que verdaderamente estoy llamado a ser: mi nombre secreto), ${ }^{34}$ sino también todo el resto de las realidades: como decía Agustín de Hipona, cuando Dios crea «hay más seres, pero en absoluto hay más Ser».

\footnotetext{
${ }^{31}$ Cardona, Carlos: Metafísica del bien y del mal, cit., pp. 122-123.
}

${ }^{32}$ Lo expresan adecuadamente estos juicios de Alberoni: «L'innamoramento tende alla fusione di due persone diverse, che conservano la propria libertà e la propria inconfondibile specificità. Noi vogliamo essere amati in quanti o esseri unici, straordinari, insostituibili. Nell'amore non dobbiamo limitarci, ma espanderci, non dobbiamo rinunciare alla nostra essenza ma realizzarla, non dobbiamo tarpare le nostre possibilità, ma portarle a compimento. Anche la Persona amata ci interessa perché è assolutamente diversa, inconfrontabile. E tale deve restare, splendente e sovrana mente libera. Noi siamo affascinati da ciò che essa è, da tutto ciò che di sé ci rivela. Quindi siamo pronti ad adottare il suo punto di vista, a modificare noi stessi»... no solo sin dejar de ser quienes somos, sino siéndolo de una forma más plena, enriquecida. Alberoni, Francesco: Ti amo. Milano: R.C.S. Libri \& Grandi Opere S.p.A., 1996, pp. 193-194. Trad. cast.: Te amo. Barcelona: Gedisa, 1997, p. 152.

${ }^{33}$ Lo ilustran una vez más, estas palabras, en absoluto sencillas, de Cardona: «Por el contrario, el justo, el que cumple amorosamente la ley natural, identificado con la Voluntad sabia y buena que le ha señalado el camino de su plenitud y de su gozo total, puede decirse que no está sometido a la ley, en el sentido de que no la "padece", no le es violenta y coactiva, sino connatural y libremente querida: y tiene ya ahí una primicia de su felicidad terminal, cuando su voluntad esté definitivamente identificada por el amor con el origen mismo de su ser, en una cuasi (participada) identidad de ser y obrar, de acto y contenido, por la intencional identificación con Dios». CARDONA, Carlos: Metafísica del bien y del mal, cit., p. 143.

34 «When you fell in love with Michael, you were given a great gift: your love took you past appearances and granted you a perception of his true self, who he's meant to be in the deepest sense of the word. You discovered his "secret name."

Those who love have been granted the special privilege of seeing with incredible intensity the beauty of the one they love while others see primarily his exterior acts, and particularly his failings. At this moment, you see Michael more clearly than does any other living human being». Hildebrand, Alice von: By Love Refined: Letters to a Young Bride. Manchester - New Hampshire: Sophia Institute Press, 1989, p. 12. 
Precisamente San Agustín esclarece de forma expresa la dificultad aludida:

Seguir a Dios es el deseo de la beatitud; poseerlo, la beatitud misma. Pero lo seguimos amándolo, lo poseemos no transformándonos en Él, sino unidos admirablemente a Él con el espíri$\mathrm{tu}$, rodeados e inmersos en la luz de su verdad. ${ }^{35}$

\subsection{El paso al amor electivo}

De vuelta a nuestro discurso, antes de la elección primera nos estamos moviendo, incluso si se trata del hombre -mujer o varón-, dentro en un amor real, pero no de la categoría suficiente para recibir la calificación de propia y radicalmente humano.

Su fundamento es la naturaleza en el sentido primigenio y más restringido de este vocablo, es decir, en cuanto excluye - $\mathrm{O}$, al menos no incluye- la libertad; y su punto de referencia, como sugerí, la relación de lo amado con uno mismo. ${ }^{36}$

En la terminología que he adoptado para este escrito, podría recibir la calificación de primum "volitum", por cuanto responde al ejercicio de la voluntad, pero antes o al margen de la libre elección que dota de cualidad moral a los actos voluntarios, en virtud precisamente de la índole de la preferencia primordial que subyace a cada uno de ellos. Es lo que de ordinario se conoce como amor natural.

Por el contrario, el amor electivo es resultado de una elección libre, que implica entendimiento y voluntad, y que, por eso, cuando es correcto:

a) Tiene como base la bondad real de las cosas y, sobre todo, la grandeza mucho más sublime de las personas, percibidas a su vez por un entendimiento cabal.

b) Se sitúa en un plano superior, en el que el término naturaleza ha sido purificado hasta alcanzar su más propia acepción (desconocida, según parece, para Aristóteles, al menos en la plenitud de sus connotaciones); de suerte que lo natural para el hombre es ahora el ejercicio equilibrado e inteligente de su libertad.

c) Resulta susceptible de calificación ética, como ya anticipé.

\footnotetext{
${ }^{35}$ Agustín de Hipona: De moribus I, 11, 18.

${ }^{36}$ No quiero repetir lo que ya expuse en una nota anterior. Es decir, hasta qué extremo este amor, necesariamente finito, resulta precario: tanto si se erigen en fundamento de sí mismo como, muchísimo más, si pretende constituirse en cimiento o base de cualquier otro amor, pues entonces se manifiesta más aún su endeblez constitutiva.
} 
d) Engloba en cierto modo, a la par que eleva, ${ }^{37}$ al amor natural antes mencionado, aunque contraríe en parte a la naturaleza caída en cuanto caída. ${ }^{38}$

e) Y, por tanto, establece - para el ser humano- la auténtica y natural culminación del amor natural. ${ }^{39}$

\subsection{Condiciones ineludibles}

A su vez, para que nazca este tipo de amor resulta imprescindible: $a$ ) que el entendimiento haya madurado lo suficiente para apreciar la realidad como tal y, por ende, lo bueno-en-sí y no solo el bien para mí; b) y que la voluntad opte por el bien en cuanto bien y, como consecuencia, cuando sea el caso, del otro en cuanto otro, en lugar de centrarse reduplicativa y electivamente en el propio yo. ${ }^{40}$

Según apunté, ciertos autores interpretan esta opción -la que corresponde al primum electum en su acepción más propia- apelando al momento originario de la libertad en el que el hombre se decide por Dios, eligiéndolo como objeto radical y fin último de toda su existencia.

Y así -viene a decir Kierkegaard-, la libertad se nos da con esta condición: que en el mismo instante en que se presenta como libertad de elección entre Dios y nosotros mismos - es decir, en el primer instante en que hay real uso de razón, y mil veces más después, si el tiempo de la vida terrena se prolonga-, se apresura incondicionalmente a actuar, ligándose sin restricciones por su elección al Absoluto. Es decir, se pone ante Dios de una manera activa, haciéndole entrega de ese ser y de esa libertad que, en el momento de la creación, Él nos donó para que se la ofrendáramos.

De esta suerte - prosigue Kierkegaard-, el milagro del amor infinito es que Dios nos dé el ser amoroso y nuestra misma libertad, y luego se dirija a nosotros como un aspirante a nuestro amor, como un modesto pretendiente, casi como un mendigo, pidiéndonos que enderecemos electivamente hacia Él la libertad y el amor que Él mismo nos ha otorgado.

\footnotetext{
${ }^{37}$ Sigo hablando exclusivamente del amor electivo correcto; el incorrecto, al que más tarde apelaré, también engloba al amor natural (y al primum volitum), pero en lugar de ensalzarlo, en cierto modo lo degrada y degrada también a su sujeto.

${ }^{38}$ Considero de la máxima importancia la aclaración de que el amor electivo correcto se opone a la naturaleza humana en cuanto caída, y no en sí misma. Pues, como todo lo creado, también el hombre ama naturalmente a Dios más que a sí mismo, justo en la medida en que Él -intimius intimo meo- me es en cierto modo más connatural que mi propio ser: sólo en Dios encuentro mi plena identidad.

${ }^{39}$ Volveré sobre esa afirmación.

${ }^{40}$ La voluntad, no los apetitos sensibles, por fuerza referidos a sí mismos, aunque aptos para ser reconducidos por la voluntad hacia el bien inteligible o de la persona como persona.
} 
Para concluir: la seriedad eterna de la vida - la opción total, el aut-aut definitivo- está toda aquí, en elegir a Dios enseguida y sobre todo, sobre mí mismo y sobre mi propia libertad, que es lo más íntimo y noble que poseo. En esa predilección por Dios, el hombre (que en apariencia se pierde) conquista radicalmente -y de forma creciente en las elecciones sucesivas que confirman y refuerzan a la primera- su propia libertad y su capacidad de amar: su mismo ser individual y completo. De modo que lo que enriquece esencial y operativamente a la persona es la relación amorosa que entabla con el mismo Dios personal - su voluntario estar ante Él-y con las demás personas, en la medida en que, al menos implícitamente, las refiere a Dios. ${ }^{41}$

El acto originante del primum electum podría también dibujarse, pues en el fondo desemboca en lo mismo, como la primera y radical respuesta libre a lo bueno en sí, creadora de un hábito paulatinamente más firme, que lleva a la disposición de ignorar o poner en sordina el propio yo (en cuanto yo), y a situarse en camino de amar con plena conciencia a Dios, y a las restantes personas - incluida la propia- en, por y desde Dios. ${ }^{42}$

Por eso, aunque la cuestión es delicada, me atrevería a afirmar que quien ama de veras (y subrayo hasta el infinito ese de veras) no puede hacerlo sin estar, implícitamente y de un modo no fácil de comprender, amando a Dios, que es el fundamento del ser y la bondad de toda otra realidad; 43 también porque amar mal - pecar, en expresión de la moral clásica- consiste justamente en romper el lazo que liga cual-

\footnotetext{
${ }^{41}$ Benedicto XVI expone una idea bastante similar casi el comienzo de su primera Encíclica: «Nos Dei caritati credidimus - sic praecipuam vitae suae electionem declarare potest christianus. Ad initium, cum quis christianus fit, nulla est ethica voluntas neque magna quaedam opinio, verumtamen congressio datur cum eventu quodam, cum Persona quae novum vitae finem imponit eodemque tempore certam progressionem [...]. Quoniam prior nos Deus dilexit (cfr 1 Io 4, 10), nunc non est iam tantum "praeceptum" amor, verum est responsio erga amoris donum, quo Deus nobis occurrit». Benedicto XVI: Deus Caritas est, núm. 1.

42 «La ley natural dirige los actos humanos a la adquisición de la virtud, y la virtud es lo que hace buena a la persona, en cuanto determinación estable y difícilmente removible del amor electivo, que se fija amorosamente en el fin último libremente elegido, en cuanto intensificación y rectitud del amor a Dios, identificación creciente con el Amor. La ley natural determina los contenidos que la libertad debe dar a sus actos, para mantenerse como actos libres que superan el "amor natural" a la felicidad [entendida fundamentalmente como dicha o deleite supremo], en cuanto derivados de la elección primordial y suprema por la que la persona ama a Dios como infinitamente digno de ser amado por sí mismo, y como respuesta debida al amor infinitamente generoso y liberal con que Dios me ha hecho libre y capaz de amar». Cardona, Carlos: Metafísica del bien y del mal, cit., p. 144. ${ }^{43}$ En cierto modo, lo apuntaba ya Platón: «Quien hasta aquí haya sido instruido en las cosas del amor, tras haber contemplado las cosas bellas en ordenada y correcta sucesión, descubrirá de repente, llegando ya al término de su iniciación amorosa, algo maravillosamente bello por naturaleza [...] algo que, en primer lugar, existe siempre y perece, ni crece ni decrece; en segundo lugar, no es bello en un aspecto y feo en otro [...]. ¿Qué debemos imaginar, pues, si le fuera posible a alguien ver la belleza en sí, pura, limpia sin mezcla, no mezclada [...], si pudiera contemplar la divina belleza en sí, específicamente única?» PLatón: Simposio, 210, 211.
} 
quier realidad finita con Dios, para detenerse de forma excluyente en la criatura y negar a Dios el amor debido. ${ }^{4}$

\section{Algunos rasgos peculiares del "primum electum"}

Como advertí, entre este primum de la voluntad libre y el correspondiente-asimétrico hábito del entendimiento existen al menos tantas diferencias como semejanzas. Señalaré, de manera simultánea, algunas de ellas.

\subsection{Signo de desarrollo, también orgánico}

1) Antes que nada, en ambos casos la conquista de la madurez de la propia potencia (entendimiento o voluntad) se encuentra precedida por el desarrollo orgánico pertinente y por un conjunto de operaciones de la misma facultad y de las que la prosiguen o anteceden en el ámbito sensible: los sentidos, para el entendimiento; los apetitos, para la voluntad; unos y otros, en fin de cuentas, para la acción conjunta de ambas facultades espirituales y el cortejo de las sensibles, que es lo que de ordinario tiene lugar.

Todo ello prefigura con más o menos intensidad, aunque sin jamás determinarla, la dirección que presumiblemente tomará el acto de elección originaria a que vengo aludiendo y el hábito de él derivado.

En lo que ahora nos atañe, la proporción en que tales actividades hagan desarrollarse la voluntad y los apetitos sensibles en el sentido correcto, tornará más hacedera, aunque no inevitable, la opción por el bien en cuanto tal, en el que tenderá a desenvolverse - con sus retrocesos, dudas y rectificaciones - el conjunto de la existencia de quien así ha escogido.

Dejando a un lado lo relativo a la inteligencia, y con conciencia del peligro que tal omisión lleva consigo, resulta bastante claro que la orientación afectivo-volitiva de un niño propiciará, en un sentido o en otro, la elección por la realidad (y, al me-

\footnotetext{
${ }_{44}$ Precisamente por ser un autor serio, pero al que difícilmente cabría calificar como partidista, recogemos estas nuevas palabras de Alberoni: «Per continuare ad amare bisogna che la persona amata sia sempre, in parte, trasfigurata. Appaia, cioè, "nella luce dell'essere" in cui noi vediamo lo splendore delle cose come sono. È qualcosa che ha a che fare con l'umiltà, un sentimento prossimo al religioso. E ha qualcosa di religioso anche il rispetto e il timore con cui ci avviciniamo a lei. Perché essa ci è infinitamente vicina ma, nello stesso tempo, infinitamente lontana e infinitamente desiderabile. E sappiamo che, se non ci amasse, saremmo perduti. Allora vediamo, come in un bagliore, come avrebbe potuto essere la nostra vita se non ci fossimo incontrati, se non ci avesse amato, se non ci amasse. E proviamo un brivido di paura. Grazia, miracolo, stupore, paura, sono tutte emozioni che avvicinano l'amore all'esperienza religiosa». Alberoni, Francesco: Ti amo, cit., p. 242.
} 
nos de forma implícita, por Dios, como Realidad suprema, presente en las restantes realidades) o por sí mismo.

En la sociedad actual, es bastante frecuente que ese chico reciba el fuerte influjo:

a) De una cultura que hace del propio yo el centro y punto de referencia de todo el universo.

b) De unos padres que, por ignorancia probablemente no culpable de lo que es el verdadero amor, por falta de fortaleza, por comodidad o por un simple dejarse llevar, no dirijan al muchacho hacia la búsqueda de lo bueno en sí y, por tanto, del otro en cuanto otro (y de sí mismo también en cuanto otro). Sino que, mediante una excesiva profusión de premios y concesiones, lo inclinen a obrar -incluso cuando actúa materialmente bien - por la recompensa obtenida con tales actos o por temor al castigo.

Con lo que, en fin de cuentas, lo están centrando en el propio yo y dificultando que aprecie la bondad intrínseca y constitutiva de la realidad y, sobre todo, de las personas.

Llevando la cuestión al límite, para ese chico no existiría otro bien que el bienpara-sí. Y, en efecto, sin el menor tremendismo, el bonum honestum de los clásicos parece haberse desvanecido en nuestra cultura... y no solo para los niños.

En tales circunstancias, no es difícil que, a la hora de que un chiquillo elija entre Dios (y los demás) o él mismo, de manera no del todo consciente, sino cuasi determinada por la vida que ha llevado, la opción por su propio yo se encuentre muy favorecida, mientras que le resulte bastante ardua una verdadera y cabal elección del bien de los demás, con auténtico olvido de sí, que es lo único que lo llevaría a su perfección y a su felicidad: ${ }^{45}$ y esto, incluso en un clima de religiosidad más o menos auténtica, en la medida en que esta es posible en las circunstancias a que venimos aludiendo, pues la gracia nunca sustituye a la naturaleza.

\subsection{No siempre fácil de lograr y hacer crecer}

a) Al contrario de lo que sucedía con el entendimiento, esta vez la intervención de la voluntad es neta, determinante y cuasi tautológica, pues se trata justo de realizar una elección voluntaria y libre, aunque tal vez no plenamente consciente de toda su amplitud y consecuencias.

\footnotetext{
${ }^{45}$ Aduzco de pasada, entre las muchas posibles, esta afirmación de Taulero, que tanto gustaba a San Francisco de Sales: «Cuando se le preguntaba dónde había encontrado a Dios, decía: "allí donde me dejé a mí mismo; y allí donde me encontré a mí mismo, perdí a Dios"»».
} 
Pero, si no yerro, ahora la orientación natural a querer a Dios por su bondad constitutiva - por encima de todo; y a los demás, incluido uno mismo, por amor a Dios-, se encuentra bastante más contrarrestada que en el caso del entendimiento: le sirve de obstáculo la caída original, los pecados personales y casi una entera civilización que tiende a exaltar el propio ego de forma contranatural y contracultural, si por cultura entendemos lo que de veras mejora al ser humano.

Como consecuencia, y por decirlo de algún modo, la libertad y la persona toda tienen en nuestros tiempos que empeñarse de un modo mucho más activo, profundo e intenso para optar por el bien en sí - poniendo las bases de la felicidad futura-, que cuando se limitaron a permitir o no impedir que se instaurara el primum cognitum; aunque, como he explicado otras veces, y no podía ser de un modo distinto, el establecimiento y la consolidación de los dos hábitos se encuentren mutuamente relacionados, como lo están a su vez la verdad y el bien. ${ }^{46}$

b) Además, suponiendo que la opción haya sido correcta, la misma dinámica de la voluntad, que engloba, afecta y se ve afectada por la totalidad de la persona y de cuanto la rodea, hace del hábito-virtud recién constituido algo mucho más lábil. Es preciso, por tanto, un constante refuerzo con actos de buen amor, puesto que el hábito perfeccionador de la voluntad se halla mucho más amenazado que el primum cognitum por acciones contrarias, que buscan infranaturalmente la exaltación del yo. ${ }^{47}$

c) Como consecuencia, al menos a primera vista y si observamos cuanto sucede a nuestro alrededor, en las circunstancias actuales resulta más sencillo que este hábito - el "auténtico" primum electum - no llegue a instaurarse; que se debilite una vez constituido; que sea hostigado por acciones opuestas; que se vea de nuevo fortalecido por el arrepentimiento; que se pierda de forma más o menos neta por una reversión inmediata o progresiva del hombre sobre sí mismo... y que pueda de nuevo ser recuperado por un acto suficientemente intenso de opción por el bien: ¡he ahí una de las mayores maravillas de la libertad humana, su capacidad de rehacer el pasado!

\footnotetext{
46 «El acto sustancial, el acto primero del filosofar incluye virtualmente el sentido mismo de la vida; igual que el acto de fe, se ordena al objeto de la voluntad, que es el bien, como a su fin. Y, por tanto, en la posición de ese acto filosófico primero concurren las dos potencias del espíritu, intelecto y voluntad, con sus hábitos respectivos. Y por la misma razón hay una inclinación natural a poner rectamente ese acto teorético primero, de modo que conduzca a la Verdad que tiene razón de Fin: una inclinación que es de ley natural, en cuanto que guarda esencial relación al principio y al destino de nuestra existencia». Cardona, Carlos: Metafísica de la opción intelectual, cit., p. 26.

${ }^{47}$ Infra-naturalmente, como dejé dicho, porque lo propio de la condición de persona, así llamada justo para realzar su grandeza, es la orientación hacia el bien ajeno con olvido de sí misma.
} 
Cuando, en el mundo de hoy, hablamos de hedonismo, consumismo, pragmatismo, etc., estamos apelando, aun sin saberlo, al hecho que aquí expongo un tanto drásticamente. ${ }^{48}$

\section{3. "Correcto" o "incorrecto"}

Por fin, y en espera de las explicaciones con que cerraré la segunda parte de este escrito, parece necesario apuntar los motivos del uso reiterado de adjetivos como "correcto", "incorrecto" y otros similares, para referirme tanto al primum cognitum como, sobre todo, al primum electum.

Lo expongo por ahora de manera muy sintética.

\subsubsection{Auténtico "primum cognitum"}

En virtud de su propia naturaleza, la inteligencia humana tiende a conocer la realidad como es en sí, de manera suficiente, aunque imperfecta.

Por consiguiente, el hábito que le permite ejercer adecuadamente esa función se encuentra a favor de ella, constituye su perfeccionamiento primigenio y natural $\mathrm{y}$, por cuanto genera conocimiento real, reclama con todo derecho la denominación de primum "cognitum".

Al contrario, la in-disposición "habitual" que lleva a percibir las distintas realidades en función de mis propios intereses no merece tal apelativo -el de primum "cognitum"-, puesto que, en sentido fuerte y radical, impide conocer la realidad como propiamente es: la des-realiza, cabría decir, al tornarla relativa al propio yo

\footnotetext{
${ }^{48}$ Todo lo cual, y mucho más, aunque, como es lógico, expresado con menos tecnicismos, parece encontrarse en estos párrafos de Benedicto XVI, escogidos entre bastantes otros similares: "Quomodo fingere nobis in re possumus hoc ascensionis et purificationis iter? Quo pacto amor vivi valet, ut eius humana divinaque promissio plane compleatur? Primam magni ponderis indicationem reperire possumus in Cantico Canticorum, videlicet uno Veteris Testamenti librorum, bene cognito a mysticis. Secundum hodie vigentem interpretationem carmina hunc in Librum inclusa primitus fuerunt cantus amoris, fortasse principio dedicati Hebraeorum nuptiarum celebritati, ubi coniugalis efferendus erat amor. His in adiunctis plurimum id ipsum docet quod per eundem librum duae diversae voces "amorem" indicantes deteguntur. Ante omnia vocabulum habemus "dodim" - pluralis forma qua amor adhuc incertus profertur, nempe in condicione generalis cuiusdam inquisitionis. Huic autem vocabulo deinceps sufficitur verbum "ahabà", quod in Veteris Testamenti interpretatione Graeca vox similis sonitus "agape" substituit, quae, prout iam vidimus, indicium proprium amoris est facta pro biblica rerum conceptione. Contra amorem indefinitum et adhuc inquirentem, hoc verbum experimentum exprimit amoris qui nunc vere fit alterius hominis inventio, excedendo indolem personalem, ad proprium commodum proclivem, quae antea manifesto dominabatur. Nunc alterius hominis curatio fit amor et sollicitudo pro eo. Non se ipsum amplius quaerit, immersionem in felicitatis ebrietatem; verum amati hominis quaerit bonum: abdicatio evadit quae ad sacrificium parata est quin immo illud conquirit». Benedicto XVI: Deus Caritas est, núm. 6.
} 
y, como consecuencia, dando al verbo conocer su significado más propio, la torna in-cognoscible.

\subsubsection{Verdadero "primum electum"}

En lo que atañe a la voluntad sucede algo análogo: semejante y más desemejante.

Por naturaleza, esta facultad predispone a su sujeto a apreciar lo bueno en sí de manera también adecuada; y esto implica respetar la jerarquía real de los bienes, amando más los más altos - y de manera absoluta al Bien Absoluto- y subordinando a ellos los de menor calibre.

De forma que, aunque se trate de una cuestión no fácil de captar a primera vista, sólo el primum electum cuyo término-principio radical es Dios - el primum electum "correcto" o "adecuado", con la terminología que vengo empleando- permite un ejercicio de la voluntad acorde con su naturaleza.

En el extremo opuesto, la opción radical por el yo, mientras no se rectifique, desestabiliza la jerarquía de los bienes, los torna relativos a cada persona, e impide amarlos según su valía real -en cuanto bienes en sí-, para apreciarlos tan sólo en función de los propios intereses subjetivos.

Por lo que, hablando de nuevo con el máximo rigor y por más que la afirmación pueda escandalizar, sólo el primum electum "adecuado" hace justicia a la naturaleza de la voluntad (tendente a apreciar el bien en sí) y, por consiguiente, sólo a él habría que reservar el apelativo de primum electum... y más todavía el de primum - proprie et realiter! - "volitum". 49

\footnotetext{
${ }^{49}$ Como es sabido y estudiaré en la segunda parte, las acciones por las que escojo el mal —bajo la razón de simple bien-para-mí, pues el mal en cuanto mal nunca puede elegirse - contrarían la natural inclinación de la voluntad y de la libertad: en estricto rigor, y aun siendo el resultado de una elección, no deberían calificarse ni de voluntarias ni de libres, por cuanto se oponen a la íntima naturaleza y al desarrollo de la voluntad-libertad.
} 